\title{
EXTENSION OF THE STANDARD VISIBILITY FUNCTION TO INTERVALS OF I MILLIMICRON BY THIRD-DIFFER- ENCE OSCULATORY INTERPOLATION
}

\author{
By Deane B. Judd
}

\section{ABSTRACT}

The two empiric representations (Tyndall-Gibson and Walsh) of the visibility of radiant energy yield curves which fail to pass exactly through the values at every $10 \mathrm{~m} \mu$ adopted as standard; hence, they can not serve as means of obtaining interpolated values. By the method of osculatory interpolation the visibility function is represented as a series of parabolas of the third degree which join at the specified values so as to have a common first derivative at the junction point. The discontinuities in derivatives of higher order which exist at the junction points are sufficiently small to be of no consequence.

Since the adoption of the Gibson-Tyndall ${ }^{1}$ recommended visibility function as the international standard ${ }^{2}$ two empiric formulas have been proposed for its approximate representation, one by Tyndall and Gibson ${ }^{3}$ and the other, which is of the same type, but with a somewhat better choice of constants, by Walsh. ${ }^{4}$ Such empiric formulas as these have obvious uses ${ }^{5}$ and if a similar formula were at hand which fitted the adopted values of visibility exactly, it would be of somewhat more extended use than either of the formulas already proposed; for example, it would serve to yield interpolated values of perfect continuity possessing continuous derivatives of all orders. It is not to be supposed, of course, that interpolation by such a formula, or by any other method, graphical or mechanical, yields any information concerning the true course of the standard visibility function between the specified points. In fact, that course is wholly unspecified, and there are a large number of smooth curves to be drawn through these intervals. It has been found convenient in the work of the National Bureau of Standards to adopt arbitrarily a single one of these curves. The interpolated values adopted are found by a method superior to any graphical interpolation because the values may be reproduced at any time anywhere, and it is believed that this method is superior to solutions by other formulas for interpolation because it combines continuity in function and in first derivative with

1 K. S. Gibson and E. P. T. Tyndall, The Visibility of Radiant Energy, B. S. Sci. Paper No. 475, p. 174; 1923.

Proc. International Commission on Illumination, 6th meeting, Geneva, pp. 67 and 232; July, 1924.

E. P. T. Tyndall and K. S. Gibson, Visibility of Radiant Energy Equation, J. Opt. Soc. Am. and Rev. Sci. Inst., 9, p. 403; 1924.

J. W. T. Walsh, Visibility of Radiant Energy Equation, J. Opt. Soc. Am. and Rev. Sci. Inst., 11, pp. 111-112; 1925 .

S For example, the Tyndall-Gibson formula was used by Ives in computing radiant luminous efficiency (H. E. Ives, The Luminous Properties of the Black Body, J. Opt. Soc. Am. and Rev. Sci. Inst., 12, pp. $75-78 ; 1926)$. 
considerable computational convenience. Indeed, the ease of applying this method is so great that the labor involved differs little from that of the graphical method.

The method used is interpolation by the third-difference, osculatory formula developed by Karup. ${ }^{6}$ Application of this formula, interval by interval, results in a series of parabolas of the third degree which join each other at the specified values of the function in such a way as to yield a continuous curve having a continuous first derivative; derivatives of higher order are discontinuous at the specified points to a greater or less degree according as differences of higher order than the second are great or small. ${ }^{7}$ Although Karup presented a method of applying this formula by computing from the leading major differences (see, for example, Table 1) the leading minor differences (that is, the leading differences referring to the nine interpolated values), and then deriving the desired interpolated values by continuous addition, the present interpolation of the visibility function was performed by actually finding the products indicated in the formula and taking their sum. In this way it was found possible with the aid of a computing machine to obtain nine interpolated values and to check them by an independent method in about 15 minutes $;^{8}$ it seems doubtful whether the continuous addition method would be much more expeditious.

If $V_{\lambda}$ be the visibility for wave length, $\lambda$, and $\Delta_{1} V_{\lambda_{0-10}}, \Delta_{2} V_{\lambda_{o-10}}$ and $\Delta_{3} V_{\lambda_{0-10}}$ be, respectively, the first, second, and third leading major differences as exemplified in the first row of Table 1 for $\lambda_{o}=550 \mathrm{~m} \mu$, then we compute by the third-difference osculatory formula the interpolated values within the wave-length interval, $\lambda_{o}$ to $\lambda_{o}+10$, as:

$$
V_{\lambda}=V_{\lambda_{o}-10}+K_{1} \Delta_{1} V_{\lambda_{o}-10}+K_{2} \Delta_{2} V_{\lambda_{o}-10}+K_{3} \Delta_{3} V_{\lambda_{o-10}}
$$

where:

$$
\begin{aligned}
& \dot{K}_{1}=\left(\lambda-\lambda_{o}+10\right) / 10 \\
& K_{2}=\left(\lambda-\lambda_{o}+10\right)\left(\lambda-\lambda_{o}\right) / 200 \\
& K_{3}=\left(\lambda-\lambda_{o}\right)^{2}\left(\lambda-\lambda_{o}-10\right) / 2,000
\end{aligned}
$$

Since we wish at present merely to extend the visibility function to values for every millimicron, it is necessary only to find by interpolation nine new values within each $10 \mathrm{~m} \mu$ interval; hence the coefficients, $K_{1}, K_{2}$, and $K_{3}$, may be completely evaluated for this purpose by setting in succession $\lambda-\lambda_{0}$ equal to $1,2, \ldots$. Table 3 gives such values of the coefficients, $K_{1}, K_{2}$, and $\dot{K}_{3}$. Table 4 gives the details of the computation for the wave-length interval,

6 J. Karup, On a New Mechanical Method of Graduation, Trans. 2d Int. Actuarial Congress, p. 83; 1898. J. W. Glover, Derivation of the United States Mortality Table by Osculatory Interpolation, Quarterly Publications of the American Statistical Assoc., 12, p. 90; 1910.

7 The term, osculatory, applies with more aptness to interpolation by the fifth (and higher) difference formulas than to the third-difference formula because for these formulas the second derivative as well as the first is continuous at the specified values, which insures that the successive parabolas join so as to have a common osculating circle at the point of junction. The third-difference formula is also commonly referred to as an osculatory formula because Karup used that term and because it is derived by argument similar to that leading to the formulas involving fifth differences, or differences of higher order. We might have used the fifth-difference formula here, but since, due to the regularity of the standard visibility function, the resulting values would not differ appreciably from those by the third-difference formula, the added labor would not have resulted in any practical gain.

8 The check was carried out by taking the differences in the ascending order rather than in the descending order as indicated by the formula. In general, the resulting products need not be found; they are discovered to be already evaluated incidental to the determination of interpolated values in descending order for uther wave lengths; the check consists, therefore, of assembling in different groupings, for addition, products already found. (See Tables 1,2 and 4.) 
550 to $560 \mathrm{~m} \mu$, together with the check by the ascending differences whose computation is indicated in Table 2 . The leading ascending differences, $\nabla_{1} V_{\lambda_{0+20}}, \nabla_{2} V_{\lambda_{0+20}}$ and $\nabla_{3} V_{\lambda_{o+20}}$, for $\lambda_{o}=550 \mathrm{~m} \mu$, appear in the first row of the table.

The values of the visibility function obtained in this manner for every millimicron are given in Table 5 , together with the values for every $10 \mathrm{~m} \mu$ (bold-face type) from which the interpolated values were computed. ${ }^{2}$ The function defined, interval by interval, by the third-difference osculatory, interpolation formula is, as mentioned before, continuous and possesses a continuous first derivative. The derivatives of higher order, however, are not continuous through the specified points at every $10 \mathrm{~m} \mu$. Nevertheless, since no marked irregularities occur in the standard values of visibility, these discontinuities in derivatives of higher order are of small magnitude and may be neglected.

TABLE 1.-Computation of the leading descending differences, $\lambda_{\mathrm{o}}=550 \mathrm{m \mu}$

\begin{tabular}{|c|c|c|c|c|}
\hline$\lambda$ in $m_{\mu}$ & $V_{\lambda}$ & $\Delta_{1} V_{\lambda}$ & $\Delta_{2} V_{\lambda}$ & $\Delta_{3} V_{\lambda}$ \\
\hline $\begin{array}{l}540 \\
550 \\
560\end{array}$ & $\begin{array}{r}0.954 \\
.995 \\
.995\end{array}$ & $\begin{array}{r}+0.041 \\
.000 \\
-\quad 043\end{array}$ & $\begin{array}{r}-0.041 \\
-.043\end{array}$ & -0.002 \\
\hline 570 & .952 & & & \\
\hline
\end{tabular}

TABLE 2.-Computation of the leading ascending differences, $\lambda_{\mathrm{o}}=550 \mathrm{m \mu}$

\begin{tabular}{|c|c|c|c|c|}
\hline$\lambda$ in $\mathrm{m} \mu$ & $V_{\lambda}$ & $\nabla_{1} V_{\lambda}$ & $\nabla_{2} V_{\lambda}$ & $\nabla_{3} V_{\lambda}$ \\
\hline $\begin{array}{l}570 \\
560 \\
550 \\
540\end{array}$ & $\begin{array}{r}0.952 \\
.995 \\
.995 \\
.954\end{array}$ & $\begin{array}{r}+0.043 \\
-.000 \\
-.041\end{array}$ & $\begin{array}{r}-0.043 \\
-.041\end{array}$ & +0.002 \\
\hline
\end{tabular}

TABLE 3.-Coefficients, $K_{1}, K_{2}$, and $K_{3}$, for interpolation to tenths by the thirddifference, osculatory, interpolation formula:

$V_{\lambda}=V_{\lambda_{0}}{ }^{-10}+K_{1} \Delta_{1} V_{\lambda_{0}}{ }^{-10}+K_{2} \Delta_{2} V_{\lambda_{o}} o^{-10}+K_{3} \Delta_{3} V_{\lambda} o^{-10}$

\begin{tabular}{|r|r|r|c|}
\hline$\lambda-\lambda_{0}$ & \multicolumn{1}{|c|}{$K_{1}$} & \multicolumn{1}{|c|}{$K_{2}$} & \multicolumn{1}{|c|}{$K_{3}$} \\
\hline 1 & & & \\
\cline { 1 - 3 } & +1.1 & +0.055 & -0.0045 \\
2 & +1.2 & +.120 & -.0160 \\
3 & +1.3 & +.195 & -.0315 \\
4 & +1.4 & +.280 & -.0480 \\
5 & +1.5 & +.375 & -.0625 \\
6 & +1.6 & +.480 & -.0720 \\
7 & +1.7 & +.595 & -.0735 \\
8 & +1.8 & +.720 & -.0640 \\
9 & +1.9 & +.855 & -.0405 \\
\hline
\end{tabular}

The first and last intervals were filled in by assuming the visibility for this purpose to be 0.000012 and 0.000015 at 370 and $780 \mathrm{~m} \mu$, respectively. 
TABIE 4.-Example of interpolation of the visibility function by the third-difference, osculatory formula, descending differences; checle by ascending differences

$$
\begin{gathered}
\text { For } \lambda_{0}=550 \mathrm{~m} \mu \text { we may write from Table } 1: \\
V_{\lambda}=0.951+0.041 K_{1}-0.041 K_{2}-0.002 K_{3}
\end{gathered}
$$

The coefficients, $K_{1}, K_{2}$, and $K_{3}$, may be found in Table 3

\begin{tabular}{|r|r|r|r|r|}
\hline$\lambda$ in $\mathrm{m}_{\mu}$ & $+0.041 K_{1}$ & $-0.011 K_{2}$ & $-0.002 K_{3}$ & \multicolumn{1}{|c|}{$V_{\lambda}$} \\
\hline 551 & +0.045100 & -0.002255 & +0.000009 & 0.996854 \\
552 & +.049200 & -.004920 & +.000032 & .098312 \\
553 & +.053300 & -.007995 & +.000663 & .999368 \\
554 & +.057400 & -.011480 & +.000096 & 1.000016 \\
555 & +.061500 & -.015375 & +.000125 & 1.000250 \\
556 & +.065600 & -.019680 & +.000144 & 1.000064 \\
557 & +.069700 & -.024395 & +.000147 & .999452 \\
558 & +.073800 & -.029520 & +.000128 & .998408 \\
559 & +.077900 & -.035055 & +.000081 & .996925 \\
\hline
\end{tabular}

Check by ascending differences: From Table 2 we write:

$$
V_{\lambda}=0.952+0.043 K_{1}^{\prime}-0.043 K_{2}^{\prime}+0.002 K^{\prime}{ }_{3}
$$

The coefficients, $K_{1}{ }^{\prime}, K_{2}{ }^{\prime}$, and $K_{3}{ }^{\prime}$, may be found in Table 3 by reading the values of the coefficients, $K_{1}, I_{2}$, and $K_{3}$, for $10-\lambda+\lambda_{0}$

\begin{tabular}{|r|r|r|r|r|}
\hline \multicolumn{1}{|c|}{ in $\mathrm{m}_{\mu}$} & $+0.043 K_{1}^{\prime}$ & $-0.043 K_{2}^{\prime}$ & $+0.002 K_{3}^{\prime}$ & \multicolumn{1}{|c|}{$V_{\lambda}$} \\
\hline 551 & +0.081700 & -0.036765 & -0.000081 & 0.996854 \\
552 & +.077400 & -.030960 & -.000128 & .998312 \\
553 & +.073100 & -.025585 & -.000147 & .999368 \\
554 & +.068800 & -.020640 & -.000144 & 1.000016 \\
555 & +064500 & -.016125 & -.000125 & 1.000250 \\
556 & +.060200 & -.012040 & -.000096 & 1.000064 \\
557 & +.055900 & -.008385 & -.000063 & .999452 \\
558 & +.051600 & -.005160 & -.000032 & .998408 \\
559 & +.047300 & -.002365 & -.000009 & .996926 \\
\hline
\end{tabular}


TABLE 5.-The standard visibility function cxtended to values for every millimicron. by third-difference osculatory interpolation

\begin{tabular}{|c|c|c|c|c|c|c|c|c|c|c|c|}
\hline $\begin{array}{l}\lambda \\
\mathrm{m} \mu\end{array}$ & $V_{\lambda}$ & $\stackrel{\lambda}{\lambda}$ & $V_{\lambda}$ & in $\begin{array}{c}\lambda \\
\mathrm{m}_{\mu}\end{array}$ & $V_{\lambda}$ & in ${ }^{\lambda}{ }_{\mu}$ & $V_{\lambda}$ & $\stackrel{\lambda}{\text { in }} \stackrel{\lambda}{\mathrm{m}_{\mu}}$ & $V_{\lambda}$ & in $\stackrel{\lambda}{m}$ & $V_{\lambda}$ \\
\hline 380 & 0.00004 & 150 & 0.038 & 520 & 0.710 & 590 & 0.757 & 660 & 0.061 & 730 & $0.0005 ?$ \\
\hline $\begin{array}{l}1 \\
2 \\
3 \\
4 \\
5 \\
6 \\
7 \\
8 \\
9\end{array}$ & $\begin{array}{l}.000045 \\
.000049 \\
.000054 \\
.000059 \\
.000064 \\
.000071 \\
.000080 \\
.000090 \\
.000104\end{array}$ & $\begin{array}{l}1 \\
2 \\
3 \\
4 \\
5 \\
6 \\
7 \\
8 \\
9\end{array}$ & $\begin{array}{l}.0399 \\
.0418 \\
.0438 \\
.0459 \\
.0480 \\
.0502 \\
.0525 \\
.0549 \\
.0574\end{array}$ & $\begin{array}{l}1 \\
2 \\
3 \\
4 \\
5 \\
6 \\
7 \\
8 \\
9\end{array}$ & $\begin{array}{l}.7277 \\
.7449 \\
.7615 \\
.7776 \\
.7932 \\
.8082 \\
.8225 \\
.8363 \\
.8495\end{array}$ & $\begin{array}{l}1 \\
2 \\
3 \\
4 \\
5 \\
6 \\
7 \\
8 \\
9\end{array}$ & $\begin{array}{l}.7449 \\
.7327 \\
.7202 \\
.7076 \\
.6949 \\
.6822 \\
.6694 \\
.6565 \\
.6437\end{array}$ & $\begin{array}{l}1 \\
2 \\
3 \\
4 \\
5 \\
6 \\
7 \\
8 \\
9\end{array}$ & $\begin{array}{l}.0574 \\
.0539 \\
.0506 \\
.0475 \\
.0446 \\
.0418 \\
.0391 \\
.0366 \\
.0343\end{array}$ & $\begin{array}{l}1 \\
2 \\
3 \\
4 \\
5 \\
6 \\
7 \\
8 \\
9\end{array}$ & $\begin{array}{l}.000482 \\
.00044 \\
.000415 \\
.000338 \\
.000360 \\
.000335 \\
.000313 \\
.000291 \\
.000270\end{array}$ \\
\hline 390 & .00012 & 460 & .060 & 530 & .882 & 600 & .631 & 070 & .032 & 740 & .00025 \\
\hline $\begin{array}{l}1 \\
2 \\
3 \\
4 \\
5 \\
6 \\
7 \\
8 \\
9\end{array}$ & $\begin{array}{l}.000138 \\
.000155 \\
.000173 \\
.000193 \\
.000215 \\
.000241 \\
.000272 \\
.000308 \\
.000350\end{array}$ & $\begin{array}{l}1 \\
2 \\
3 \\
4 \\
5 \\
6 \\
7 \\
8 \\
9\end{array}$ & $\begin{array}{l}.0627 \\
.0654 \\
.0681 \\
.0709 \\
.0739 \\
.0769 \\
.0836 \\
.0872\end{array}$ & $\begin{array}{l}1 \\
2 \\
3 \\
4 \\
5 \\
6 \\
7 \\
8 \\
9\end{array}$ & $\begin{array}{l}.8739 \\
.8851 \\
.8956 \\
.8056 \\
.9149 \\
.9238 \\
.9320 \\
.9398 \\
.9471\end{array}$ & $\begin{array}{l}1 \\
2 \\
3 \\
4 \\
5 \\
6 \\
7 \\
8 \\
9\end{array}$ & $\begin{array}{l}.6182 \\
.6054 \\
.5926 \\
.5797 \\
.5668 \\
.5539 \\
.5410 \\
.5282 \\
.5156\end{array}$ & $\begin{array}{l}1 \\
2 \\
3 \\
4 \\
5 \\
6 \\
7 \\
8 \\
9\end{array}$ & $\begin{array}{l}.0299 \\
.0280 \\
.0263 \\
.0247 \\
.0232 \\
.0219 \\
.0206 \\
.0194 \\
.0182\end{array}$ & $\begin{array}{l}1 \\
2 \\
3 \\
4 \\
5 \\
6 \\
7 \\
8 \\
9\end{array}$ & $\begin{array}{l}.000231 \\
.000214 \\
.000198 \\
.000185 \\
.000172 \\
.0001180 \\
.000148 \\
.000138 \\
.000130\end{array}$ \\
\hline 400 & .0004 & 470 & .091 & 540 & .954 & 610 & .503 & 680 & .017 & 850 & .00912 \\
\hline $\begin{array}{l}1 \\
2 \\
3 \\
4 \\
5 \\
6 \\
7 \\
8 \\
9\end{array}$ & $\begin{array}{l}.00045 \\
.00049 \\
.00054 \\
.00059 \\
.00064 \\
.00071 \\
.06080 \\
.00090 \\
.00104\end{array}$ & $\begin{array}{l}1 \\
2 \\
3 \\
4 \\
5 \\
6 \\
7 \\
8 \\
9\end{array}$ & $\begin{array}{r}.0950 \\
.0992 \\
.1035 \\
.1080 \\
.1126 \\
.1175 \\
.1225 \\
.1278 \\
.1333\end{array}$ & $\begin{array}{l}1 \\
2 \\
3 \\
4 \\
5 \\
6 \\
7 \\
8 \\
9\end{array}$ & $\begin{array}{l}.9604 \\
.9661 \\
.9713 \\
.9760 \\
.9803 \\
.9840 \\
.9873 \\
.9902 \\
.9928\end{array}$ & $\begin{array}{l}1 \\
2 \\
3 \\
4 \\
5 \\
6 \\
7 \\
8 \\
9\end{array}$ & $\begin{array}{l}.4905 \\
.4781 \\
.4658 \\
.4535 \\
.4412 \\
.4291 \\
.4170 \\
.4049 \\
.3929\end{array}$ & $\begin{array}{l}1 \\
2 \\
3 \\
4 \\
5 \\
6 \\
7 \\
8 \\
9\end{array}$ & $\begin{array}{l}.01585 \\
.01477 \\
.01376 \\
.01281 \\
.01192 \\
.01108 \\
.01030 \\
.00956 \\
.00886\end{array}$ & $\begin{array}{l}1 \\
2 \\
3 \\
4 \\
5 \\
6 \\
7 \\
8 \\
9\end{array}$ & $\begin{array}{l}.000111 \\
.000103 \\
.000096 \\
.0000000 \\
.000084 \\
.0000078 \\
.0000069 \\
.000064\end{array}$ \\
\hline 410 & .0012 & 480 & 139 & 550 & .995 & 620 & .381 & 690 & .0082 & 760 & .00008 \\
\hline $\begin{array}{l}1 \\
2 \\
3 \\
4 \\
5 \\
6 \\
7 \\
8 \\
9\end{array}$ & $\begin{array}{l}.00138 \\
.00156 \\
.00174 \\
.00195 \\
.00218 \\
.00244 \\
.00274 \\
.00310 \\
.00352\end{array}$ & $\begin{array}{l}1 \\
2 \\
3 \\
4 \\
5 \\
6 \\
7 \\
8 \\
9\end{array}$ & $\begin{array}{r}.1448 \\
.1507 \\
.1567 \\
.1629 \\
.1693 \\
.1761 \\
.1833 \\
.1909 \\
.1991\end{array}$ & $\begin{array}{l}1 \\
2 \\
3 \\
4 \\
5 \\
6 \\
7 \\
8 \\
8\end{array}$ & $\begin{array}{r}.9969 \\
.9983 \\
.9994 \\
1.0000 \\
1.0002 \\
1.0001 \\
.9995 \\
.9984 \\
.9969\end{array}$ & $\begin{array}{l}1 \\
2 \\
3 \\
4 \\
5 \\
6 \\
7 \\
8 \\
9\end{array}$ & $\begin{array}{r}.3690 \\
.3570 \\
.3449 \\
.3329 \\
.3210 \\
.3092 \\
.2977 \\
.2864 \\
.2755\end{array}$ & $\begin{array}{l}1 \\
2 \\
3 \\
4 \\
5 \\
6 \\
7 \\
8 \\
9\end{array}$ & $\begin{array}{l}.00759 \\
.00705 \\
.00656 \\
.00612 \\
.00572 \\
.00536 \\
.00503 \\
.00471 \\
.00440\end{array}$ & $\begin{array}{l}1 \\
2 \\
3 \\
4 \\
5 \\
6 \\
7 \\
8 \\
9\end{array}$ & $\begin{array}{l}.000056 \\
.000052 \\
.000048 \\
.0000045 \\
.000042 \\
.000033 \\
.05033 \\
.000035 \\
.000032\end{array}$ \\
\hline 120 & .0040 & 490 & .208 & 360 & .995 & 630 & .265 & 800 & .0041 & 770 & .00003 \\
\hline $\begin{array}{l}1 \\
2 \\
3 \\
4 \\
5 \\
6 \\
7 \\
8 \\
9\end{array}$ & $\begin{array}{l}.00726 \\
.00806 \\
.00889 \\
.00976 \\
.01066\end{array}$ & $\begin{array}{l}1 \\
2 \\
3 \\
4 \\
5 \\
6 \\
7 \\
8 \\
9\end{array}$ & $\begin{array}{r}.2173 \\
.2270 \\
.2371 \\
.2476 \\
.2586 \\
.2201 \\
.2823 \\
.2951 \\
.3087\end{array}$ & $\begin{array}{l}1 \\
2 \\
3 \\
4 \\
5 \\
6 \\
7 \\
8 \\
9\end{array}$ & $\begin{array}{r}.9926 \\
.9898 \\
.9865 \\
.9828 \\
.9786 \\
.9741 \\
.9691 \\
.9638 \\
.9581\end{array}$ & $\begin{array}{l}1 \\
2 \\
3 \\
4 \\
5 \\
6 \\
5 \\
8 \\
9\end{array}$ & $\begin{array}{r}.2548 \\
.2450 \\
.2354 \\
.2261 \\
.2170 \\
.2082 \\
.1996 \\
.1912 \\
.1830\end{array}$ & $\begin{array}{l}1 \\
2 \\
3 \\
4 \\
5 \\
6 \\
7 \\
5 \\
9\end{array}$ & $\begin{array}{l}.00381 \\
.00355 \\
.00332 \\
.00310 \\
.00291 \\
.00273 \\
.00256 \\
.00241 \\
.00225\end{array}$ & & 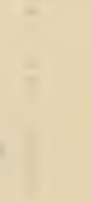 \\
\hline 430 & .0116 & 300 & . 323 & 570 & .852 & 610 & .175 & 710 & .0021 & & \\
\hline $\begin{array}{l}1 \\
2 \\
3 \\
4 \\
5 \\
6 \\
7 \\
8 \\
9\end{array}$ & $\begin{array}{l}.01257 \\
.01358 \\
.01463 \\
.01571 \\
.01684 \\
.01800 \\
.01920 \\
.02043 \\
.02170\end{array}$ & $\begin{array}{l}1 \\
2 \\
3 \\
4 \\
5 \\
6 \\
7 \\
8 \\
9\end{array}$ & $\begin{array}{r}.3382 \\
.3544 \\
.3714 \\
.3890 \\
.4073 \\
.4259 \\
.4450 \\
.4642 \\
.4836\end{array}$ & $\begin{array}{l}1 \\
2 \\
3 \\
4 \\
5 \\
6 \\
7 \\
8 \\
9\end{array}$ & $\begin{array}{l}.9455 \\
.9386 \\
.9312 \\
.9235 \\
.9154 \\
.9069 \\
.8981 \\
.8890 \\
.8796\end{array}$ & $\begin{array}{l}1 \\
2 \\
3 \\
4 \\
5 \\
6 \\
7 \\
8 \\
9\end{array}$ & $\begin{array}{r}.1672 \\
.1596 \\
.1523 \\
.1452 \\
.1382 \\
.1316 \\
.1251 \\
.1188 \\
.1128\end{array}$ & $\begin{array}{l}1 \\
2 \\
3 \\
4 \\
5 \\
6 \\
7 \\
8 \\
9\end{array}$ & $\begin{array}{l}.001954 \\
.001821 \\
.001699 \\
.001587 \\
.001483 \\
.001387 \\
.001297 \\
.001212 \\
.001130\end{array}$ & & \\
\hline 40 & .023 & 510 & .503 & 580 & 0.870 & 650 & .107 & 720 & .00105 & & \\
\hline $\begin{array}{l}1 \\
2 \\
3 \\
4 \\
5 \\
6 \\
7 \\
8 \\
8\end{array}$ & $\begin{array}{l}.0243 \\
.0257 \\
.0270 \\
.0281 \\
.0298 \\
.0313 \\
.0329 \\
.0345 \\
.0362\end{array}$ & $\begin{array}{l}1 \\
2 \\
3 \\
4 \\
5 \\
6 \\
7 \\
8 \\
9\end{array}$ & $\begin{array}{r}.5229 \\
.5436 \\
.5648 \\
.5865 \\
.6082 \\
.6299 \\
.6511 \\
.6717 \\
.6914\end{array}$ & $\begin{array}{l}1 \\
2 \\
3 \\
4 \\
5 \\
6 \\
7 \\
8 \\
9\end{array}$ & $\begin{array}{l}.8600 \\
.8496 \\
.8388 \\
.8277 \\
.8163 \\
.8046 \\
.7928 \\
.7809 \\
.7690\end{array}$ & $\begin{array}{l}1 \\
2 \\
3 \\
4 \\
5 \\
6 \\
7 \\
8 \\
9\end{array}$ & $\begin{array}{l}.1014 \\
.0961 \\
.0910 \\
.0862 \\
.0816 \\
.0771 \\
.0729 \\
.0688 \\
.0848\end{array}$ & $\begin{array}{l}1 \\
2 \\
3 \\
4 \\
5 \\
6 \\
7 \\
8 \\
9\end{array}$ & $\begin{array}{l}.000975 \\
.000907 \\
.006815 \\
.000788 \\
.000736 \\
.000688 \\
.000644 \\
.000601 \\
.000580\end{array}$ & & \\
\hline
\end{tabular}


The values of Table 5 result from carrying the computation out to at least one more significant figure than has been reported; they differ from the values which would result from the rigorous application of the formula,therefore, by an amount in every case less than 1 in the last figure reported.

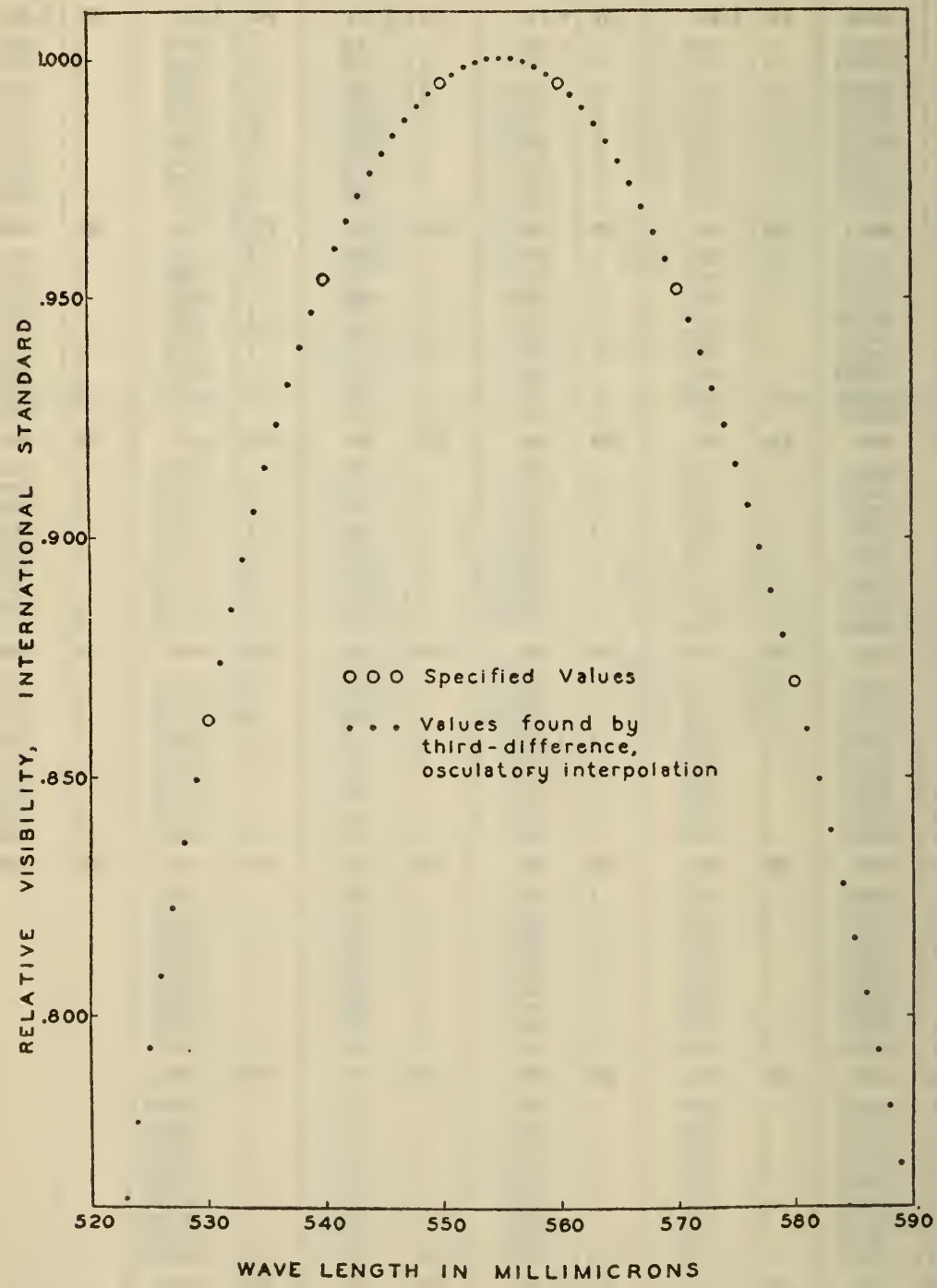

FIGURE 1.-An example of interpolation of the standard visibility function by the third-difference, osculatory formula

A portion of the visibility curve near its maximum is chosen for a demonstration of the smoothness of the interpolated values

It is, perhaps, of interest to note that the maximum value of the visibility function according to third-difference osculatory interpolation (see Table 4, Table 5, or fig. 1) is nearly unity, and hence agrees to within 3 in the fourth decimal with the value given by 
Gibson and Tyndall from graphical interpolation; and, to be sure, the wave length of the maximum visibility is also very closely 555 $\mathrm{m} \mu$ as they found.

Figure 1 serves to indicate graphically for a restricted wave-length range the regularity of the interpolated values which are shown as small circles. The values originally specified at every $10 \mathrm{~m} \mu$ are plotted as large circles.

Acknowledgment is due Miss Mabel E. Brown for carrying out the computations.

Wıshington, December, 1930. 